\title{
Aerobic Capacity of Students with Different Levels of Physical Activity as Assessed by IPAQ
}

\author{
by \\ Władysław Mynarski ${ }^{1}$, Michał Rozpara ${ }^{1}$, \\ Krzysztof Czaplaㄹ, Wiesław Garbaciak ${ }^{3}$
}

\begin{abstract}
International Physical Activity Questionnaire (IPAQ) has become one of the world's most valuable tools for measuring physical activity in different groups or populations.

The relationship between regular, moderate-intensity physical activity and health parameters including physical fitness and aerobic capacity has been clearly proven by numerous investigations throughout the world.

The aim of the present study was to determine the magnitude of differences in absolute \& relative $\left(l \times \mathrm{min}^{-1}, \mathrm{ml} \times \mathrm{kg}^{-}\right.$ $\left.{ }^{1} \times \mathrm{min}^{-1}\right) \mathrm{VO}_{2}$ max, by using the Astrand-Ryhming normogram in students aged 19 to 24 years, depending on their weekly energy expenditure (METmin $\times$ week $\left.^{-1}\right)$, as diagnosed with IPAQ.

The significance of differences in aerobic capacity between highly and moderately active students was evaluated. The Pearson correlation coefficient was calculated as a measure of the strength of the correlation between the above parameters in female and male groups.

$\mathrm{VO}_{2}$ max was significantly higher in male and female participants, with a high level of physical activity, as determined through IPAQ criteria.
\end{abstract}

Key words: physical activity, aerobic capacity, students, questionnaire

\section{Introduction}

Physical activity (PA) is widely regarded as a primary component of a healthy lifestyle; its level is considered one of the best measures of health (Astrand, 1992; Bouchard et al., 1994; Kemper, 1995). Thus, the term PA is of particular importance in the field of recreation and physical education.

Kozłowski and Nazar (1995) assume that PA, for example, physical effort concerns skeletal muscle work and a whole spectrum of associated functional changes that occur in the organism, and are expressed as enhanced energy expenditure (Anshel et al., 1991; Bouchard and Shephard, 1994). Among all advantages of PA, an increase in aerobic capacity is considered the most beneficial to health. Relationships between PA and aerobic power have been the subject of numerous research studies. However, a reliable assessment of PA level poses several methodological setbacks, since the form, type, frequency, volume, and intensity should all be determined (As-

1 - Department of Tourism, Recreation and Management, the Jerzy Kukuczka Academy of Physical Education in Katowice, Poland

2 - Sports Centre, the University of Technology in Gliwice, Poland

3 - Department of the Theory and Methodology of Physical Education, the Jerzy Kukuczka Academy of Physical Education in Katowice, Poland 
trand, 1992; Melanson and Freedson, 1996; Corbin et al., 2006). In recent years, questionnaires have been used for this purpose, as this type of survey is easy and quick to perform. Nevertheless, PA level estimation using a questionnaire has both advantages and disadvantages (Freedson and Melanson, 1996; Sjøstrom et al., 2000; Craig et al., 2003; Stasiołek and Jegier, 2003), and among the latter, there is a tendency to over-estimate self-reported PA level, particularly by adolescents (Mynarski et al., 2007; Biernat et al., 2008).

International Physical Activity Questionnaire (IPAQ) has become one of the world's most valuable tools for measuring physical activity in different groups or population. Booth (2000) defined IPAQ as the only reliable method of physical activity estimation in large populations of developed and developing countries. At present, the questionnaire is widely used to investigate physical activity levels among different groups and populations (Hallal et al., 2003; Gomez et al., 2005; Suchomel et al., 2008), and its accuracy and reliability are controlled (Craig et al., 2003; Arvidsson et al., 2005; Eklund et al., 2006; Hagstromer et al., 2006; Kurtze et al., 2008). There is a short and a long version of the questionnaire; the short version is suitable for use in national and regional surveillance systems. The Polish version of the IPAQ was accepted in 2004 by the IPAQ Executive Committee, and was used in the present study to assess the correlation between PA level and aerobic capacity.

The aim of our study was to investigate whether student allocation in high and moderate level physical activity groups, based on self-reported PA levels obtained using the IPAQ, confirm the widely accepted hypothesis that increased physical activity enhances physical fitness, and mainly aerobic capacity. It was assumed that confirmation of the above will constitute indirect evidence in support of the reliability of IPAQ self-report.

The magnitudes of differences in aerobic capacity between students with high and moderate physical activity levels were determined.

It was hypothesized that aerobic capacity of students with a high level of physical activity, as determined by the IPAQ, would be higher compared to that of moderately active study participants.

Material \& methods

The study group comprised of 123 female (body height $165.38 \pm 5.99 \mathrm{~cm}$, body mass $59.35 \pm 8.32 \mathrm{~kg}$ ) and 135 male (body height $178.20 \pm 6.32 \mathrm{~cm}$, body mass
$73.67 \pm 10.70 \mathrm{~kg}$ ) students of Silesian Universities, aged 19 to 24 years. Participation in the study was voluntary; the candidates were enrolled if no contraindications were seen during the exercise test protocol (Astrand-Ryhming).

The students' physical activity (physical effort typically undertaken during a usual week in the month preceding the questionnaire survey) was assessed based on the Polish short version of the IPAQ (Biernat et al., 2007). The obtained data was scored according to the guidelines by Cull et al. (2002) and Craig et al. (2003).

The short IPAQ version includes seven questions about the respondent's PA in a usual week. Statistical analysis was performed on their answers to questions concerning physical activity of vigorous, moderate, and low intensity. Walking at a speed of

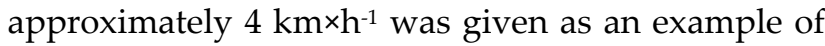
a low-level intensity PA, but which a respondent found physically difficult to perform (Crige et al., 2003). To facilitate the identification of vigorous and moderate intensity PA, examples were provided with each question according to Ainsworth et al.'s (2000) compendia of different forms of physical activity.

Data scoring was based on MET values of intensity levels, as suggested by the IPAQ authors. The values of 3.3 METs, 4.0 METs, and 8.0 METs represented low-, moderate-, and high-intensity activities, respectively.

The complete procedure of IPAQ data analysis consists of calculating the total volume of a given intensity level of physical activity, expressed as METmin $\times$ week $^{-1}$ scores. These are obtained by multiplying MET value of low-, moderate- or high-intensity PA by the number of days when it was undertaken and activity duration (e.g., moderate METmin $\times$ week-1 $=4.0 \times$ moderate intensity activity minutes $\times$ moderate days). Thus, weekly PA volume can be determined based on which the respondents are assigned to one of the following categories:

High PA level - individuals meeting at least one of the two criteria below:

- 3 or more days of vigorous intensity activities (total PA of at least 1500 METmin $\times$ week $^{-1}$ ),

- 7 or more days of any combination of low-, moderate- or high-intensity activities (e.g., 2 days of vigorous-, 4 days of moderate-, and 5 days of low-intensity activities (total PA of at least 3000 METmin $\times$ week $^{-1}$ ). 
- Moderate PA level - individuals meeting at least one of the two criteria below:

- 3 or more days of vigorous intensity activities of at least 20 minutes per day (total PA of 480-1500 METmin $\times$ week $^{-1}$ ),

- 5 or more days of moderate intensity activities and or low-intensity activity of at least 30 minutes per day (total PA of 495-3000 METmin $\times$ week $^{-1}$ ),

- 5 or more days of any combination of low-, moderate- or high-intensity activities (total PA of 600-3000 METmin× week $^{-1}$ ).

Low PA level - individuals who do not engage in any physical effort or fail to meet the criteria for moderate or high levels.

The overwhelming majority of the students met the criteria of high (36 women, 56 men) or moderate (84 women, 77 men) physical activity levels. Only 3 female and 2 male participants were classified as representing the low PA level, and hence they were not included in the statistical analysis.

Aerobic capacity was evaluated by the AstrandRyhming test. Both absolute $\left(1 \times \mathrm{min}^{-1}\right)$ and relative $\left(\mathrm{ml} \times \mathrm{kg}^{-1} \times \mathrm{min}^{-1}\right)$ values were considered in the statistical analysis. The significance of mean aerobic capacity differences between highly and moderately active students was assessed using the Student t-test for independent variables. Calculations were made separately for male and female subjects.

In order to verify the above statistics, correlations were determined between IPAQ datasets and aerobic capacity variables, separately for women and men, disregarding the division into physical activity groups.

\section{Results}

Mean values of variables analyzed in female and male members of highly and moderately active groups are given in Tables 1 and 2. The distribution of analyzed variables was normal.

The above facts allowed us to carry out further statistical analysis, mainly regarding the correlations between physical activity and aerobic capacity variables (significance test for differences, correlation).

Mean values of somatic parameters in male and female members of high- and moderate-level physical activity groups (body height, mass, and BMI) were similar; it can be assumed that body build did not result in significant differences between the groups. Thus, morphological features did not significantly affect the relationship between physical activity and aerobic capacity.

Data presented in Tables 1 and 2 indicate clear differences between PA volume at all intensities, as well as between aerobic capacity in male and female members of high and moderate physical activity groups, which might result from the division criteria. It should also be noted that mean scores derived for each type of intensity, as well as mean total physical activity per week, are higher for men.

Similar results were obtained regarding aerobic capacity $\left(\mathrm{VO}_{2}\right.$ max) in female and male groups (Figures 1-4).

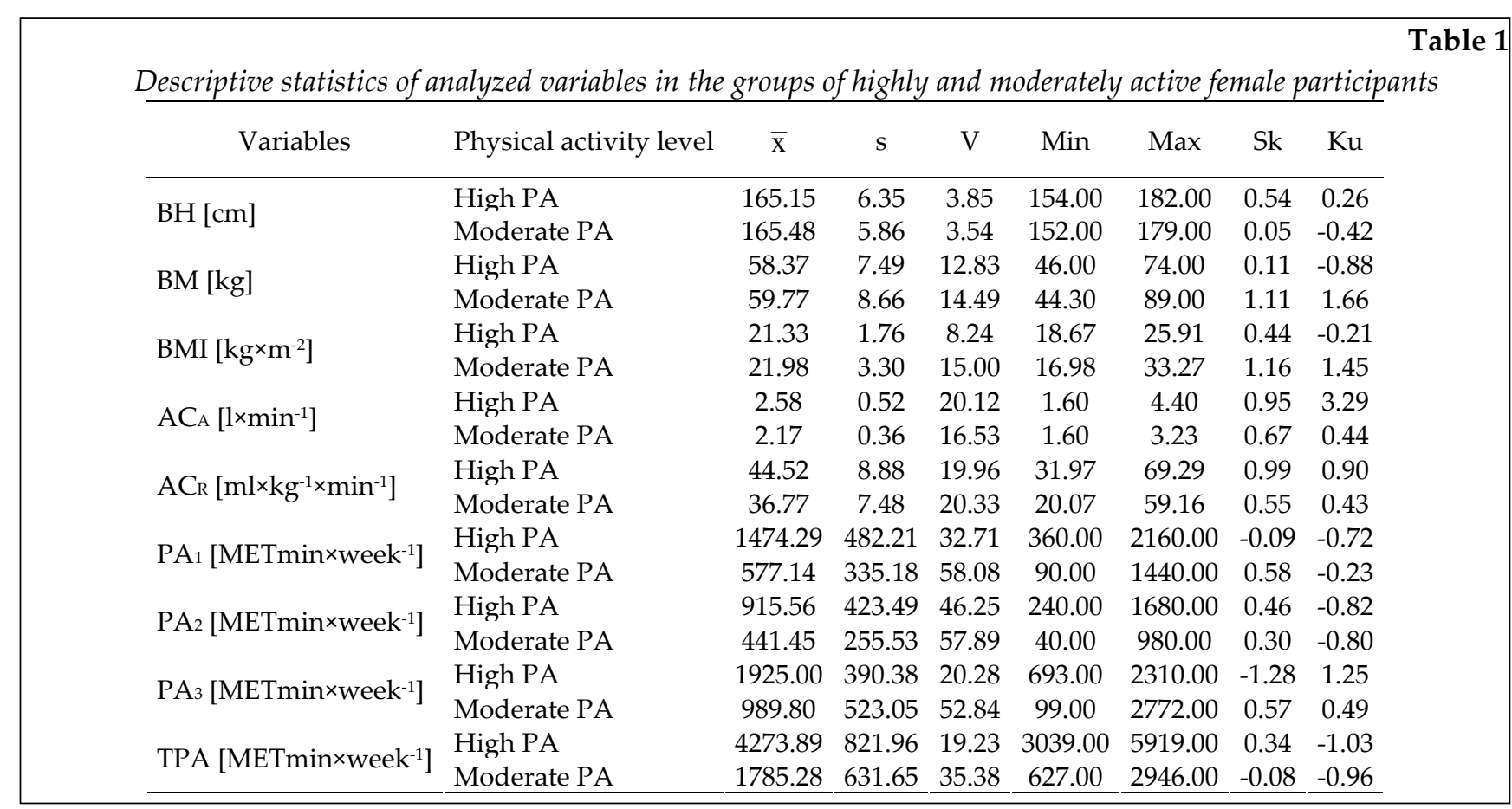


Table 2

Descriptive statistics of analyzed variables in the groups of highly-and moderately active male participants

\begin{tabular}{|c|c|c|c|c|c|c|c|c|}
\hline Variables & Physical activity level & $\overline{\mathrm{X}}$ & $\mathrm{s}$ & $\mathrm{V}$ & Min & Max & Sk & $\mathrm{Ku}$ \\
\hline \multirow{2}{*}{$\mathrm{BH}[\mathrm{cm}]$} & High PA & 177.65 & 5.29 & 2.98 & 168.50 & 192.00 & 0.55 & -0.02 \\
\hline & Moderate & 178.59 & 6.98 & 3.91 & 164.00 & 198.00 & 0.31 & 0.22 \\
\hline \multirow{2}{*}{$\mathrm{BM}[\mathrm{kg}]$} & High PA & 73.31 & 10.61 & 14.47 & 55.00 & 117.10 & 1.82 & 5.63 \\
\hline & Moderate PA & 73.93 & 10.83 & 14.65 & 51.40 & 109.10 & 0.77 & 1.06 \\
\hline \multirow{2}{*}{$\mathrm{BMI}\left[\mathrm{kg} \times \mathrm{m}^{-2}\right]$} & High PA & 23.17 & 2.56 & 11.06 & 18.81 & 33.13 & 1.46 & 3.39 \\
\hline & Moderate PA & 23.17 & 3.06 & 13.20 & 16.22 & 36.45 & 1.29 & 4.62 \\
\hline \multirow{2}{*}{$\mathrm{AC}_{\mathrm{A}}\left[1 \times \mathrm{min}^{-1}\right]$} & & 3.21 & 0.67 & 20.83 & 1.96 & 4.90 & 0.52 & -0.10 \\
\hline & Mod & 2.83 & 0.53 & 18.79 & 1.90 & 4.53 & 0.79 & 0.35 \\
\hline \multirow{2}{*}{$\mathrm{AC}_{\mathrm{R}}\left[\mathrm{ml} \times \mathrm{kg}^{-1} \times \mathrm{min}^{-1}\right]$} & Higl & 43.95 & 8.27 & 18.81 & 26.40 & 60.48 & 0.28 & -0.43 \\
\hline & Moderate PA & 38.75 & 7.18 & 18.52 & 22.91 & 63.38 & 0.84 & 1.06 \\
\hline \multirow{2}{*}{$\mathrm{PA}_{1}\left[\mathrm{METmin} \times\right.$ week $\left.^{-1}\right]$} & High PA & 1785.00 & 744.95 & 41.73 & 540.00 & 3240.00 & 0.19 & -0.88 \\
\hline & Moderate PA & 673.56 & 312.17 & 46.35 & 120.00 & 1440.00 & 0.10 & -0.79 \\
\hline \multirow{2}{*}{$\mathrm{PA}_{2}\left[\mathrm{METmin} \times\right.$ week $\left.^{-1}\right]$} & High PA & 909.26 & 438.64 & 48.24 & 120.00 & 2160.00 & 0.84 & 1.20 \\
\hline & Moderate PA & 473.43 & 237.76 & 50.22 & 120.00 & 1080.00 & 0.68 & -0.20 \\
\hline \multirow{2}{*}{$\mathrm{PA}_{3}\left[\mathrm{METmin} \times\right.$ week $\left.^{-1}\right]$} & High PA & 2046.88 & 552.16 & 26.98 & 264.00 & 2772.00 & -1.22 & 1.76 \\
\hline & Moderate PA & 990.00 & 496.73 & 50.17 & 198.00 & 2079.00 & 0.22 & -0.78 \\
\hline \multirow{2}{*}{ TPA [METmin× week $^{-1}$ ] } & High PA & 4708.67 & 1316.81 & 27.97 & 2064.00 & 7932.00 & 0.41 & -0.27 \\
\hline & Moderate PA & 2058.96 & 527.32 & 25.61 & 706.50 & 2946.00 & -0.51 & -0.38 \\
\hline
\end{tabular}

The above results confirm (Table 3) significant differences $(p<0.001)$ between absolute and relative aerobic capacity values in both highly and moderately active subjects, irrespective of gender.

To verify the observed intergroup differences, the Pearson's $r$ linear correlation coefficient was calculated for female and male participants, disregarding their physical activity level. The strength and direction of the correlation between physical activity and aerobic power in our study shows a statistical sig- nificance $(p<0.05)$, with the exception of the relationship between $\mathrm{PA}_{2}$ and the relative value of $\mathrm{VO}_{2}$ max $\left(\mathrm{ml} \times \mathrm{kg}^{-1} \times \mathrm{min}^{-1}\right)$ in females. Correlation strength was generally greater in men, especially in case of $\mathrm{PA}_{3}$ and TPA.

\section{Discussion}

The reports of Kemper (1995), Kriska and Caspersen (1997), Corbin et al. (2006), Fogelholm et al. (2006), Graff-Iversen et al. (2007) and Kurtze et al.

Table 3

Intergroup aerobic capacity differences in female and male participants (physical activity level according to IPAQ)

\begin{tabular}{|c|c|c|c|c|c|c|c|}
\hline \multirow{2}{*}{ Variables } & \multirow{2}{*}{ Gender } & \multicolumn{2}{|c|}{ High PA } & \multicolumn{2}{|c|}{ Moderate PA } & \multirow{2}{*}{$\mathrm{t}$} & \multirow{2}{*}{$\mathrm{p}$} \\
\hline & & $\overline{\mathrm{x}}$ & $\mathrm{s}$ & $\overline{\mathrm{x}}$ & $\mathrm{s}$ & & \\
\hline \multirow{2}{*}{$\mathrm{AC}_{\mathrm{A}}\left[1 \times \mathrm{min}^{-1}\right]$} & F & 2.58 & 0.52 & 2.17 & 0.36 & -5.00 & 0.001 \\
\hline & $\mathrm{M}$ & 3.21 & 0.67 & 2.83 & 0.53 & -3.58 & 0.001 \\
\hline \multirow{2}{*}{$\mathrm{AC}_{\mathrm{R}}\left[\mathrm{ml} \times \mathrm{kg}^{-1} \times \mathrm{min}^{-1}\right]$} & $\mathrm{F}$ & 44.52 & 8.88 & 36.77 & 7.48 & -4.91 & 0.001 \\
\hline & M & 43.95 & 8.27 & 38.75 & 7.18 & -3.87 & 0.001 \\
\hline
\end{tabular}

Statistically significant differences at $\mathrm{p}<0.001$ are given in bold

Correlation coefficients between physical activities of different intensity and aerobic capacity in female and male participants

\begin{tabular}{cccc}
\hline Variables & Gender & $\mathrm{AC}_{\mathrm{A}}\left[1 \times \mathrm{min}^{-1}\right]$ & $\mathrm{AC}\left[\mathrm{ml} \times \mathrm{kg}^{-1} \times \mathrm{min}^{-1}\right]$ \\
\hline \multirow{2}{*}{$\mathrm{PA}_{1}\left[\right.$ METmin $\times$ week $\left.^{-1}\right]$} & $\mathrm{F}$ & $\mathbf{0 . 4 4}$ & $\mathbf{0 . 3 7}$ \\
& $\mathrm{M}$ & $\mathbf{0 . 5 2}$ & $\mathbf{0 . 5 4}$ \\
\hline \multirow{2}{*}{$\mathrm{PA}_{2}\left[\mathrm{METmin} \times\right.$ week $\left.^{-1}\right]$} & $\mathrm{F}$ & $\mathbf{0 . 2 2}$ & 0.20 \\
& $\mathrm{M}$ & $\mathbf{0 . 2 5}$ & $\mathbf{0 . 3 1}$ \\
\hline \multirow{2}{*}{$\mathrm{PA}_{3}\left[\mathrm{METmin} \times\right.$ week $\left.^{-1}\right]$} & $\mathrm{F}$ & $\mathbf{0 . 4 5}$ & $\mathbf{0 . 3 9}$ \\
& $\mathrm{M}$ & $\mathbf{0 . 2 4}$ & $\mathbf{0 . 2 5}$ \\
\hline \multirow{2}{*}{ TPA [METmin $\times$ week $\left.^{-1}\right]$} & $\mathrm{F}$ & $\mathbf{0 . 4 7}$ & $\mathbf{0 . 4 1}$ \\
& $\mathrm{M}$ & $\mathbf{0 . 4 2}$ & $\mathbf{0 . 4 5}$ \\
\hline
\end{tabular}

Pearson's $r$ - linear correlation coefficients at $\mathrm{p}<0.05$ are given in bold 


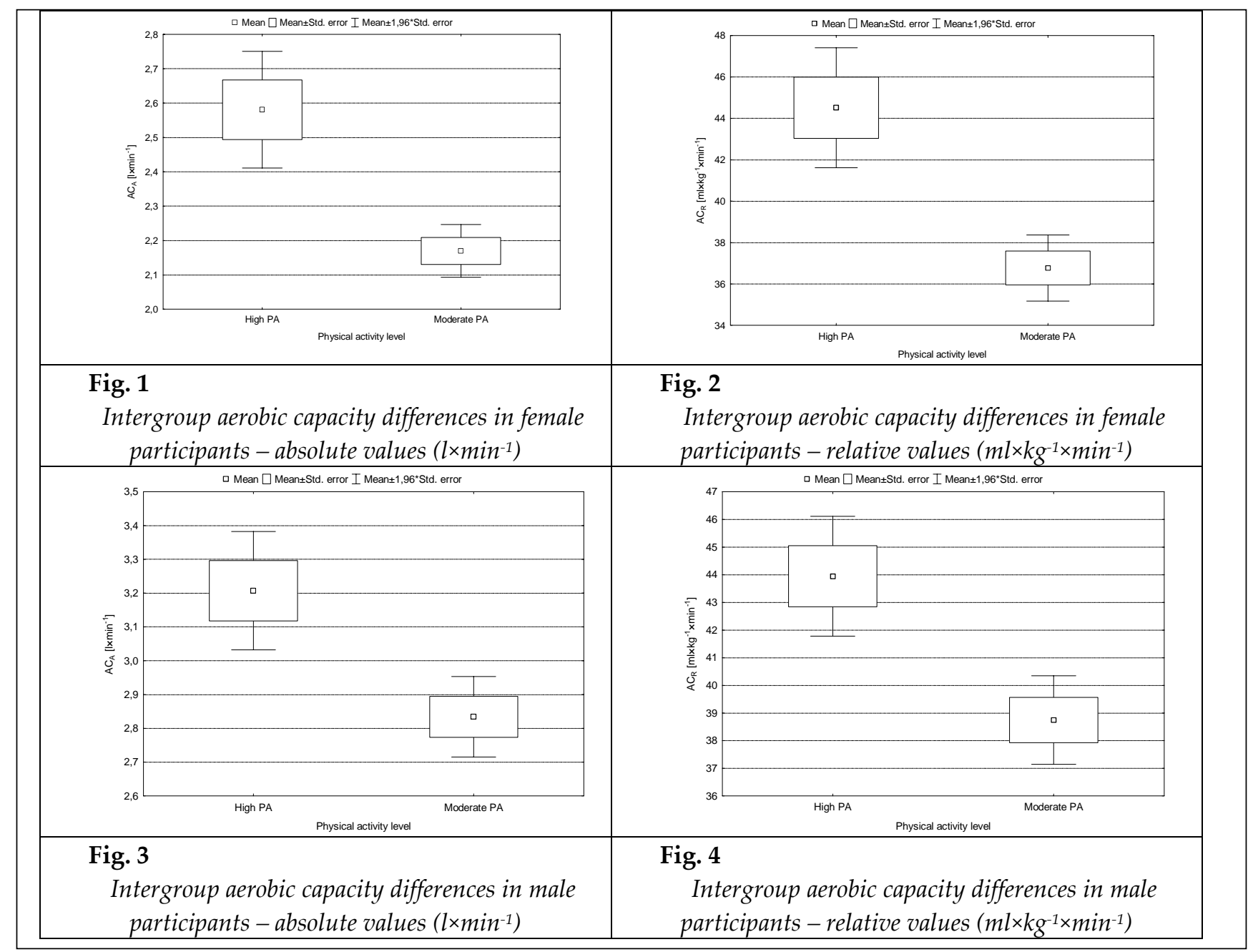

(2008) provide substantial data concerning the influence of different physical activity levels on aerobic capacity $\left(\mathrm{VO}_{2} \max \right)$. Most authors indicate that regular physical activity results in enhanced aerobic power (i.e., increased capacity of the body to transport and utilize oxygen during exercise).

The results of our investigations fully confirm the above mentioned observations. Nevertheless, the technique of physical activity assessment (IPAQ) did show the aforementioned methodological limitations, particularly regarding student allocation to high-, moderate- and low-physical activity groups. The last group only comprised a negligible percentage of the study population $(1.94 \%)$, whereas the results of investigations carried out among Polish youth indicate much higher numbers of those with low levels of physical activity (Frömel and Górna, 2001).

The outcome can be accounted for as follows:

1. Participation in the study was voluntary; students with low levels of physical activity as well as overweight and obese individuals probably abstained from PA, fearing they would reach poor results in comparison to their peer group.

2. Young people have a tendency to overestimate their PA level, especially with self-report instruments (Biernat et al., 2008; Mynarski et al., 2007).

3. The criteria of inclusion in a given physical activity level, as established by the authors of IPAQ (identical for a population aged 15 to 64 years), are probably too low for adolescents and young people.

The above reasons could all affect PA group allocation of our study. This did not have an impact on our study objectives, since highly and moderately active student groups differed regarding the frequency and volume of PA. However, we would like to emphasize the need for cautious interpretation of questionnaire survey results. Another problem related to IPAQ is the respondent's assessment of physical activity in a usual week preceding the survey, whereas, in fact, aerobic capacity is an outcome of long-term regular endurance physical exercise (Astrand, 1992; Corbin et al., 2006). However, other research results seem to suggest that physical activ- 
ity habits continue from childhood and adolescence into adulthood (Mc Elroy, 2002). According to observations of the Amsterdam Growth and Heath Longitudinal Study, PA levels affect aerobic power during puberty and later in life (Kemper, 1995). Thus, we assumed that PA levels of our study participants were similar as earlier in their life, and, consequently, their aerobic capacity resulted from long-term engagement in a given physical activity pattern.

In light of the above, we consider our results concerning higher $\mathrm{VO}_{2}$ max in female and male students with high PA levels as probable. Similar coefficients of correlation between $\mathrm{VO}_{2}$ max and $\mathrm{PA}$ evaluated by IPAQ were obtained by Kurtze et al. (2008) and Graff-Iversen et al. (2008), who investigated middle aged populations. This also seems to be confirmed by the results of several month or longer experiments investigating the effect of physical activity characterized strictly by predetermined frequency, volume, and intensity of $\mathrm{VO}_{2}$ max (Garber et al., 1992; Williford et al., 1993; Mynarski et al., 2007). Our research hypothesis has been verified, and other authors' observations were confirmed.

The study also indicates that PA volume in men is greater than in women (Frömel et al., 1999; Van Mechelen et al., 2000; Trost et al., 2002; Mynarski et al., 2007; Suchomel et al., 2008). This mostly concerns high-intensity PA, and total volume of physical activity per week. It can be suggested that, for male students, low-intensity PA constitutes a sub-threshold stimulus for aerobic capacity improvement. Female students, who less frequently engage in intensive exercise, might benefit from everyday life activities, as well as high volume and low-intensity recreation; all of which might advantageously affect or help maintain their aerobic power.

In conclusion, it should be emphasized that the correlations between different PA levels and aerobic capacity are of statistical character; and may not be observed in some individuals. Thus, only tendencies of correlations between some individual characteristics can be considered, which is in accordance with the opinions of other researchers.

Our results indicate that IPAQ is a reliable tool to differentiate between PA volume in study participants, however, the PA category inclusion limits seem too low.

\section{Conclusions}

1. IPAQ as a self-report instrument only allowed the division of study participants into highly and moderately active. The percentage of students representing the low PA level was negligible ( $2.44 \%$ of female and $1.48 \%$ of male students). Thus, the PA category inclusion limits, devised by the authors of IPAQ, seem too low.

2. Aerobic capacity of highly active students was significantly higher compared to that of moderately active participants, irrespective of gender. This has been confirmed by correlations between considered variables in female and male participants disregarding their PA levels. However, the strength of those correlations was smaller than in case of intergroup differences (highly and moderately active women and men).

3. Our results confirm the hypothesis that physical activity is an important stimulus of aerobic capacity $\left(\mathrm{VO}_{2}\right.$ max) improvement.

4. The correlations between different PA levels and aerobic capacity are of statistical significance and only relate to the investigated student group. However, they imply that a correlation between PA level and aerobic power in the general population exists.

5. Research results discussed herein confirm the chance of reliable PA level differentiation using questionnaire tools (eg., IPAQ).

\section{References}

Ainsworth B. E. et al. Compendium of physical activities: an update of activity codes and MET intensities. Med Sci Sport Exer, 2000. 32(9): 498-516.

Anshel M. H. et al. Dictionary of the sport and exercise sciences. Human Kinetics Books. Champaign, Illinois 1991.

Arvidsson D., Slinde F., Hulthen L. Physical activity questionnaire for adolescents validated against doubly labelled water. Eur J Clin Nutr, 2005. 59: 376-383.

Astrand P. O. Why exercise? Med Sci Sport Exer, 1992. 24(2): 153-162. 
Biernat E. et al. Assessment of physical activity by applying IPAQ questionnaire. Physical Education and Sport, 2008. 52: 46-52.

Biernat E., Stupnicki R., Gajewski A. K. Międzynarodowy Kwestionariusz Aktywności Fizycznej (IPAQ) - wersja polska. Physical Education and Sport, 2007. 51(1): 47-54.

Booth M. Assessment of physical activity: an international perspective. Res Q Exercise Sport, 2000. 71: 114-120.

Bouchard C., Shephard R. J. Physical Activity, Fitness, and Health: The model and key concepts. In: Physical Activity, Fitness, and Health. Eds. C. Bouchard, R. J. Sheparhd, T. Stephens. Human Kinetics, Champaign, 1994: 77-88.

Corbin Ch. B., et al. Fundamental concepts of fitness and wellness. Second edition. McGraw-Hill, New York, 2006.

Craig C. L. et al. International physical activity questionnaire: 12-country reliability and validity. Med Sci Sport Exer, 2003. 35(8): 1381-1395.

Cull A. et al. Eortc quality of life group translation procedure. EORTC quality of Life Unit Brussel 2002.

Ekelund U. et al. Criterion-related validity of the last 7-day, short form of the International Physical Activity Questionnaire in Swedish adults. Public Health Nutrition, 2006. 9: 258-265.

Fogelholm M. et al. International Physical Activity Questionnaire: Validity against fitness. Med Sci Sports Exerc, 2006. 38(4): 753-60.

Freedson P. S., Melanson E. L. Jr. Measuring physical activity. In: Measurement in Pediatric Exercise Science. Ed. D. Docherty. Human Kinetics, Champaign, 1996: 259-284.

Frömel K. et al. School youth physical activity. In: Movement and health Eds. H. Valkova, Z. Hanelova. Univerzita Palackeho, Olomouc, 1999: 29-33.

Frömel K., Górna K. Aktywność ruchowa dzieci i młodzieży regionu śląskiego. In: Tradycje i współczesność kultury fizycznej. Ed. W. Mynarski, M. Ponczek. AWF, Katowice, 2001: 51-68.

Garber C. E., McKinney J. S., Carleton R. A. Is aerobic dance an effective alternative to walk-jog exercise training? J Sport Med Phys Fit, 1992. 32(2): 136-141.

Gomez L. F. et al. Physical activity levels in adults living in Bogota (Colombia): prevalence and associated factors. Gac Sanit, 2005. 19: 206-213.

Graff-Iversen S. et al. An adapted version of the long International Physical Activity Questionnaire (IPAQ-L): construct validity in a low-income, multiethnic population study from Oslo, Norway. International Journal of Behavioral Nutrition and Physical Activity, 2007. 4: 13.

Graff-Iversen S. et al. Two short questionnaires on leisure-time physical activity compared with serum lipids, anthropometric measurements and aerobic power in a suburban population from Oslo, Norway. Eur J Epidemiol, 2008. 23(3): 167-174.

Hagströmer M., Oja P., Sjøstrom M. The International Physical Activity Questionnaire (IPAQ): a study of concurrent and construct validity. Public Health Nutrition, 2006. 9: 755-762.

Hallal P. C. et al. Physical inactivity: prevalence and associated variables in Brazilian adults. Med Sci Sport Exer, 2003. 35: 1894-1900.

Kemper H. C. G. (Ed.): The Amsterdam Growth Study. A longitudinal analysis of health, fitness, and lifestyle. Human Kinetics, Champaign, 1995.

Kozłowski S., Nazar K. (Eds.) Wprowadzenie do fizjologii klinicznej. PZWL, Warszawa 1995.

Kriska A. M., Caspersen C. J. A collection of physical activity questionnaires for health related research. Med Sci Sport Exer, 1997. 29: S3-205. 
Kurtze N., Rangul V., Hustvedt B. E. Reliability and validity of the international physical activity questionnaire in the Nord-Trøndelag health study (HUNT) population of men. BMC Med Res Methodol, 2008. 8: 63.

McElroy M. Resistance to exercise: A social analysis of inactivity. Human Kinetics, Champaign 2002.

Melanson E. L., Freedson P. S. Physical activity assessment: a review of methods. Crit Rev Food Sci Nutr, 1996. 36: 385-396.

Mynarski W. et al. Sprawność fizyczna ukierunkowana na zdrowie (H-RF) populacji Górnego Śląska. AWF, Katowice 2007.

Sjøstrom M. et al. Assessment of physical activity using IPAQ - version 4 - and activity monitors - CSA. Meas. Phys. Educ. Exerc. Sci. 2000. 4: 263-264.

Stasiołek D., Jegier A. Wybrane kwestionariusze stosowane do oceny aktywności ruchowej. Medicina Sportiva, 2003. 7(1): 19-30.

Suchomel A., Sigmundová D., Frömel K. The lifestyle of the inhabitants of the Liberec region. Human Movement, 2008. 9(1): 19-26.

Trost S. G. et al. Age and gender differences in objectively measured physical activity in youth. Med Sci Sports Exerc, 2002. 34(2): 350-355.

Van Mechelen W. et al. Physical activity of young people: The Amsterdam Longitudinal Growth and Health Study. Med Sci Sports Exerc, 2000. 32(9): 1610-1616.

Williford H. N., Scharff-Olson M., Blessing D. L. Exercise prescription for women. Special considerations, 1993. 15(5): 299-311.

\section{Corresponding author}

\section{Władysław Mynarski}

Department of Tourism, Recreation and Management;

of the Jerzy Kukuczka Academy of Physical Education in Katowice,

40-065 Katowice,

Mikołowska 72a, Poland

Phone: +48 322075169

Fax: +48322075200

e-mail: prowladek@on.pl 